\title{
Citologia Vaginal a Fresco na Gravidez: Correlação com a Citologia Corada pela Técnica de Papanicolaou
}

\author{
Fresh Wet Mount in Pregnancy: Correlation with Pap Smears
}

Amadeu Ramos da Silva Filho

RESUMO

Objetivo: analisar o conteúdo vaginal utilizando o exame citológico a fresco na primeira consulta pré-natal em mulheres com ou sem queixas genitais e correlacionar os resultados com os encontrados na citologia corada pela técnica de Papanicolaou. A microscopia direta durante a gravidez deve ser valorizada e reconhecida como método propedêutico capaz de diagnosticar, de forma imediata, 90\% dos casos de vaginose bacteriana, candidose e tricomonose.

Métodos: estudo prospectivo em 216 gestantes, selecionadas em ambulatório de pré-natal no periodo de 30 de outubro de 2001 a 12 de novembro de 2002. Foram colhidas duas amostras do conteúdo existente no fundo de saco vaginal posterior e depositadas em lâminas de vidro para microscopia. Sobre a primeira e a segunda amostra eram colocadas uma gota de $\mathrm{NaCl}$ a $0,9 \%$ e uma de $\mathrm{KOH}$ a 10\%, respectivamente. Adicionalmente, em todas as grávidas determinou-se o $\mathrm{pH}$ vaginal e realizaram-se os testes de produção das aminas com odores de pescado. O material era examinado ao microscópio em aumentos de 100 vezes, 400 vezes e excepcionalmente 1000 vezes. Foram realizados esfregaços cervicovaginais para citologia corada pelo método de Papanicolaou. A correlação entre os resultados dos métodos citológicos empregados foi realizada pelo cálculo do coeficiente kappa, que avalia a concordância para variáveis qualitativas.

Resultados: o encontro nos esfregaços a fresco de flora bacteriana normal foi de 51,8, representando o aspecto citológico mais observado e sem correspondência com os 3,7\% apurados na microscopia corada. No exame citológico direto foram observados 30,9\% de vaginose bacteriana e 7,9\% de candidose. Todavia, no Papanicolaou não foi encontrada tal equivalência, sendo as porcentagens de 0,7 e 24,3\%, respectivamente. A ausência de correlação no diagnóstico de colpite bacteriana inespecífica na microscopia direta $(17,5 \%) e$ corada $(51,3 \%)$ talvez deva-se ao subdiagnóstico de vaginose neste último método propedêutico. Os diagnósticos de tricomoníase observados em ambos os métodos citológicos (3,7 e 2,7\%) traduzem a baixa prevalência destes parasitas na gestação. O cálculo do índice kappa para avaliação da concordância entre os dois procedimentos citológicos nos diversos achados microbiológicos demonstrou baixa correlação nos diagnósticos da vaginose bacteriana e colpites bacterianas inespecíficas, bem como na identificação da flora vaginal normal.

Conclusões: embora a citologia corada apresente melhor acurácia no diagnóstico de fungos não formadores de micélios, a citologia direta a fresco demonstrou ser melhor avaliador dos elementos não epiteliais dos esfregaços vaginais. Entretanto, a microscopia corada pela técnica de Papanicolaou, por permitir melhor apreciação das células epiteliais cervicovaginais, representa o mais importante instrumento revelador das agressões e reações nucleocitoplasmáticas.

PALAVRAS-CHAVE: Pré-natal. Citologia vaginal. Infecções na gravidez. Tricomoníase. Vaginose bacteriana. 


\section{Introdução}

O uso do microscópio nos ambulatórios de pré-natal, como propedêutica imediata nas queixas vulvovaginais, representa substancial melhora na qualidade da assistência obstétrica. A pouca utilização deste valioso instrumento é observada mesmo em países desenvolvidos; os tocoginecologistas norte-americanos só o utilizam em $24 \%$ das pacientes com queixas de vaginites ${ }^{1}$. Como explicar este fato? O tempo utilizado no exame microscópico é pouco superior ao tempo que a gestante utiliza para trocar suas vestimentas; as queixas genitais na gravidez não constituem raridade, quase todas as grávidas em algum momento referem corrimento vaginal e/ou prurido, ardor e dor ao coito.

Utilizar empiricamente óvulos/cremes vaginais ou aguardar o laudo da citologia corada semanas após a colheita e, se necessário, efetuar o tratamento não representam as melhores condutas. Em 90\% dos casos o diagnóstico etiológico das queixas vulvovaginais está representado pela vaginose bacteriana, candidíase ou tricomoníase ${ }^{2}$, todas facilmente identificáveis no ato da consulta pela microscopia direta.

A ascensão de microrganismos existentes na vagina representa uma das causas da infeção das membranas, fragilizando-as, permitindo, sobretudo no terceiro trimestre gestacional, a ruptura e a interrupção da gravidez antes do termo ${ }^{3}$. A Gardnerella vaginalis e o Mobiluncus, entre outras, representam bactérias que quando não diagnosticadas e convenientemente erradicadas, principalmente após a vigésima quarta semana de prenhez, contribuem para o parto pré-termo ${ }^{4,5}$. Por vezes microrganismos existentes na cavidade vaginal da grávida atravessam as membranas ovulares íntegras, contaminam o líquido amniótico e secundariamente infectam o feto, na grande maioria através do pulmão. Este mecanismo explicaria porque a pneumonite é o achado mais freqüente de autópsia para os casos de mortes fetais relacionadas à infeção bacteriana ${ }^{2}$.

Investigar microrganismos potencialmente danosos à gravidez representa melhorar a qualidade da assistência pré-natal. Inúmeros métodos em alguns casos são utilizados, dentre eles temos

Hospital Universitário Pedro Ernesto da Universidade do Estado do Rio de Janeiro

Correspondência:

Amadeu Ramos da Silva Filho

Rua Ministro Corrêa de Melo 113, Apto 802 - Leblon

22430-110 - Rio de Janeiro - RJ

Telefax: (21) 2512-7274

e-mail: amadeu.ramos@globo.com a observação microscópica, culturas específicas, cromatografia do líquido vaginal, métodos enzimáticos, fluorimétricos e técnicas utilizando a reação em cadeia da polimerase.

Os métodos microscópicos utilizados na investigação dos microrganismos vaginais estão representados pela observação direta sem utilização de corantes, também chamado de exame a fresco, pela observação de esfregaços corados pelo Gram e a citologia corada pela técnica de Papanicolaou. Nenhum representa o padrão-ouro na identificação microbiológica vaginal, apresentando falhas nas interpretações, como veremos ao longo do trabalho. Os métodos são excludentes ou se superpõem? Qual o melhor na identificação de determinado microrganismo vaginal?

A utilização do método direto a fresco é universalmente aceita como sendo o que melhor se presta na prática ambulatorial, agilizando o diagnóstico e tratamento do corrimento vaginal, maior queixa ginecobstétrica. Além das respostas às perguntas formuladas, procuro divulgar junto aos pré-natalistas o aprendizado e utilização de tão importante instrumento propedêutico.

A proposta deste estudo foi analisar o conteúdo vaginal utilizando-se o exame a fresco na primeira consulta pré-natal em mulheres com ou sem queixas genitais e correlacionar os aspectos microscópicos encontrados com os observados na colpocitologia corada pelo método de Papanicolaou.

\section{Pacientes e Métodos}

Trabalho prospectivo do tipo ensaio clínico realizado no período de 30 de outubro de 2001 a 12 de novembro de 2002 em gestantes matriculadas no ambulatório de pré-natal do Hospital Universitário Pedro Ernesto. Foram incluídas neste estudo gestantes por ocasião da primeira consulta prénatal, em diferentes idades gestacionais, apresentando ou não queixas genitais como: corrimento, prurido vaginal e percepção de odor fétido, sobretudo durante o intercurso sexual. As transplantadas, as soropositivas para HIV e as em uso atual ou até sete dias atrás de antibiótico sistêmico e/ ou vaginal foram excluídas na observação.

Foram realizados esfregaços vaginais para exames citológicos, a fresco e corado pela técnica de Papanicolaou, de 216 gestantes. As colheitas e os exames a fresco foram efetuados pelo autor e as citologias coradas foram analisadas pelos citologistas do Departamento de Anatomia Patológica da Faculdade de Ciências Médicas da Universidade do Rio de Janeiro. Nas solicitações dos 
esfregaços corados não constavam os achados das observações diretas a fresco.

Após colocação do especulo vaginal, sem lubrificante, expunha-se a cérvice e fundos de sacos vaginais. O conteúdo vaginal, se existente, era analisado quanto às suas características físicas (cor, consistência, pH e presença de bolhas gasosas) e produção de aminas voláteis (putrescina, cadaverina e trimetilamina) com odor de pescado quando em contato com o hidróxido de potássio $(\mathrm{KOH})$ a 10\%. Com a espátula de Ayre colhia-se do fundo de saco vaginal posterior o material a ser estudado e depositava-se pequena amostra no centro de duas lâminas de vidro. Em uma delas pingava-se uma gota de solução salina fisiológica, que permite avaliação das células epiteliais, leucócitos e flora vaginal; sobre outra amostra depositava-se uma gota de solução de $\mathrm{KOH}$ a $10 \%$. Delicadamente misturava-se o material, cobriase com lamínula e levava-se imediatamente ao microscópio. Neste momento esfregaços cervicovaginais eram realizados, fixados em álcool e enviados ao laboratório de anatomia patológica para exame colpocitológico.

$\mathrm{O}$ pH vaginal foi determinado utilizando-se papel indicador Acilit ${ }^{\circledR}$ do Laboratório Merck (pH de 0,5 a 5,0) ou MN-Special ${ }^{\circledR}$ (pH de 5,5 a 9). Iniciava-se microscopia com pequeno aumento (100 vezes) proporcionando, na lâmina com solução salina, análise panorâmica quantitativa e qualitativa das células epiteliais descamadas e dos elementos não epiteliais. Na lâmina contendo $\mathrm{KOH}$ a $10 \%$, com exceção das leveduras, todas estruturas celulares têm suas membranas rompidas, facilitando o reconhecimento dos fungos. Posteriormente aumentava-se o campo microscópico para $400 X$, e por vezes 1000 vezes, para melhor avaliação da flora bacteriana, fungos e protozoários.

O microscópico utilizado foi o bi-ocular da marca Nikon com aumentos de 40X a 1000 vezes.

$\mathrm{O}$ diagnóstico de vaginose bacteriana baseou-se no encontro de pelo menos 3 dos 4 critérios propostos por Amsel et al. ${ }^{6}$ : descarga vaginal brancacenta, delgada, homogênea e uniformemente aderente; $\mathrm{pH}$ vaginal $>4,5$; odor de pescado com adição de $\mathrm{KOH}$ a 10\%; presença de pelo menos $20 \%$ de células indicadoras ou clue cells (células epiteliais com margens obscurecidas por bactérias) no exame microscópico do esfregaço vaginal. Além dos critérios acima, observava-se a quase ausência de lactobacilos de Döderlein e elementos leucocitários. A exacerbada flora bacteriana está representada por cocos e microbacilos.

A vaginite micótica está representada por descarga vaginal branca e fluida exteriorizando- se pela fúrcula vulvar ou por material branco espesso, semelhante "à nata de leite", aderido às paredes vaginais. As lâminas tratadas com soro fisiológico e $\mathrm{KOH}$ a $10 \%$ permitem observar na Candida albicans a presença de pseudo-hifas, estruturas alongadas e septadas e nas quais brotam esporos. Apresentam-se isoladas no campo microscópico ou, nas infeções mais intensas entrelaçadas constituindo verdadeiras redes.

Outros fungos, como a Geotrichum candidum, por não apresentarem micélios, necessitam maior aumento do campo microscópico para identificação dos seus endosporos, semelhantes a pequenas hifas, unindo-se entre si de forma articulada. Sua morfologia lembra a pata de inseto. A Candida glabrata apresenta formações esféricas e de pequenas dimensões, não formam endosporos e micélios in vivo. Apesar de não ser identificada no exame a fresco, é de fácil diagnóstico na citologia corada pelo método de Papanicolaou.

A presença de descarga vaginal fluida amarelo-esverdeada, freqüentemente com bolhas na superfície, nos indica da possibilidade de infeção vaginal pelo Trichomonas vaginalis. Os parasitas podem estar associados à flora bacteriana anaeróbica; nestes casos, células indicadoras estão presentes ${ }^{7}$. No exame a fresco com soro fisiológico os protozoários apresentam-se como formações ovaladas ou piriformes providos de movimentos de seus flagelos e de uma membrana ondulante em sua parte ântero-lateral que permitem seu fácil reconhecimento.

Na vaginite bacteriana inespecífica o corrimento apresentava-se levemente amarelado, por vezes fluido ou mais espesso. Na microscopia com 100 vezes observava-se aumento do número de polimorfonucleares em uma relação de mais de 10 leucócitos para cada célula epitelial vaginal. No espaço extracelular notavam-se inúmeras bactérias do tipo cocos ou bastonetes, dotados de movimentos do tipo brawniano.

$\mathrm{Na}$ anamnese as queixas genitais como presença de descarga vaginal, prurido vulvovaginal, ardência ao contato com a urina e odor fétido representavam elementos que, associados ao exame especular, auxiliavam na interpretação do exame microscópico direto.

Para análise da correlação entre os resultados da citologia vaginal direta a fresco e os da citologia vaginal corada pela técnica de Papanicolaou empregamos o índice de concordância kappa de Fleiss ${ }^{8,9}$ empregado em medidas de concordância para variáveis qualitativas, cuja interpretação é: 0,8-1 (muito bom); 0,6-0,8 (bom); 0,40,6 (moderado); 0,2-0,4 (baixo); 0-0,2 (insignificante). Este trabalho foi aprovado pela Comissão de 
Ética em Pesquisa do Hospital Universitário Pedro Ernesto da Faculdade de Ciências Médicas da Universidade do Estado do Rio de Janeiro.

\section{Resultados}

Os laudos microscópicos nas citologias a fresco e coradas pela técnica de Papanicolaou e a correlação expressa pelo índice kappa estão representados na Tabela 1 . O índice foi de $0,7 \%$ para tricomonose e de $0,2 \%$ para colpite bacteriana.

Tabela 1 - Distribuição dos resultados microscópicos nos métodos citológicos estudados e o índice de concordância kappa.

\begin{tabular}{|c|c|c|c|c|c|}
\hline \multirow[t]{2}{*}{ Aspecto microscópico } & \multirow{2}{*}{$\begin{array}{c}\text { A fresco } \\
(+)\end{array}$} & \multirow{2}{*}{$\begin{array}{c}\text { Corada } \\
(+)\end{array}$} & \multicolumn{2}{|c|}{$\begin{array}{l}\text { A fresco } \\
\text { e corada }\end{array}$} & \multirow[t]{2}{*}{$\begin{array}{c}\text { Coeficiente } \\
\text { kappa (k) }\end{array}$} \\
\hline & & & $(+)$ & $(-)$ & \\
\hline Vaginose bacteriana & 43 & 1 & 14 & 158 & 0,31 \\
\hline Candidose & 11 & 35 & 38 & 132 & 0,48 \\
\hline Colpite bacteriana & 4 & 77 & 34 & 101 & 0,26 \\
\hline Tricomonose & 3 & 1 & 5 & 207 & 0,70 \\
\hline Leptotricose & 2 & - & 1 & 213 & 0,49 \\
\hline Fusobacteriose & 5 & - & - & 211 & * \\
\hline Flora vaginal normal & 71 & - & 8 & 137 & 0,26 \\
\hline
\end{tabular}

*Não pôde ser calculado por ausência de positividade na citologia corada.

As clue cells ou células indicadoras foram observadas em todos os casos de vaginose bacteriana. Nestas, o teste da amina encontrava-se positivo em $92 \%$ das vezes e o $\mathrm{pH}$ sempre superior a cinco. A flora lactobacilar (bacilos de Döderlein) encontrava-se ausente ou sensivelmente diminuída em $98,47 \%$ das vaginoses. A presença de elementos leucocitários em $82,51 \%$ era discreta. Em $14(30,43 \%)$ dos esfregaços a fresco identificou-se presença do Mobiluncus sp.

Em todos os casos de Trichomonas vaginalis o $\mathrm{pH}$ era superior a 5, o cheiro de pescado estava presente em $77,7 \%$ e em $88,8 \%$ as células indicadoras eram observadas. Numerosos polimorfonucleares estavam presentes (>10 leucócitos/célula epitelial), constituindo em 40,3\% das vezes grumos leucocitários. Os flagelados se destacavam no campo microscópico pelos movimentos dos flagelos e de sua membrana dorsal.

Os fungos identificados, principalmente no material tratado com $\mathrm{KOH}$ a $10 \%$, eram os formadores de micélios do gênero Candida sp. Todavia, em duas gestantes identificou-se a Geotrichum candidum, representando $4,3 \%$ das micoses no grupo citológico a fresco.

\section{Discussão}

A correlação entre as eventuais queixas genitais e o ao exame especular, que possibilita observar existência de corrimento vaginal e suas características (coloração, aeração, consistência, produção de aminas voláteis), a determinação do $\mathrm{pH}$ local e o aspecto macroscópico da mucosa cervicovaginal, orienta preliminarmente o exame microscópico.

Com os dados acima descritos o obstetra leva nítida vantagem sobre o citologista, que só dispõe dos esfregaços, embora, no encaminhamento do pedido do exame, deviam ser transcritos os achados do exame vaginal.

Associado à melhor avaliação dos elementos não epiteliais do esfregaço vaginal, o exame a fresco mostrou-se superior em alguns casos à citologia corada pela técnica de Papanicolaou. A literatura refere 9,5 a $50 \%$ de prevalência da vaginose bacteriana nas mulheres grávidas ${ }^{10-13}$. A correlação deste diagnóstico com a raça/etnia refere $22,3 \%$ nas mulheres negras e $8,5 \%$ nas da raça branca ${ }^{14}$. O achado de $26,8 \%$ neste estudo está em concordância com a miscigenação das gestantes examinadas.

O esfregaço corado pela técnica de Papanicolaou revela-se inadequado como teste de rastreamento da vaginose bacteriana durante a gravide $^{15,16}$. São mencionados valores de 73 e $82 \%$ para valores preditivos positivo e negativo, respectivamente ${ }^{17}$. O diagnóstico de vaginose bacteriana em apenas 15/216 das citologias coradas em nosso material estudado demonstra claramente a fragilidade do método e que se traduz pelo coeficiente kappa de 0,3 (baixo) na correlação com o exame direto a fresco.

A microscopia com o soro fisiológico permite no aumento de 100 vezes a visualização do Mobiluncus sp um dos agentes etiológicos da vaginose bacteriana ${ }^{11,14,16,18}$. São bacilos curvos, de movimentos rápidos em espiral, do tipo sacarolhas, e de curta duração. Foram observados em $6,4 \%$ de todos os esfregaços a fresco realizados.

Não tivemos na colpocitologia corada nenhum diagnóstico de mobiluncos. Os bacilos imóveis em forma de vírgula, embora associados à presença de células indicadoras, ausência de lactobacilos e aumento do número de bactérias de fundo, necessitam para sua visualização o uso de lente de imersão, o que rotineiramente não é feito pelo citopatologista.

O encontro do Trichomonas vaginalis no exame a fresco não foi confirmado em $25 \%$ das citologias coradas, resultado próximo ao referido 
na literatura ${ }^{19}$, que sinala 30 a $40 \%$ de falha do método de Papanicolaou em identificar o flagelado. Todavia, o coeficiente kappa igual a 0,7 mostra uma boa correlação entre os dois métodos. Na microscopia direta observou-se em $62,5 \%$ dos casos de tricomoníase intensa flora cocobacilar com alguns critérios de Amsel presentes, caracterizando nítida relação com a vaginose bacteriana. Esta correspondência encontrada é maior do que a observada na literatura ${ }^{7,20}$.

A apreciação no exame a fresco de Trichomonas vaginalis e levedura do tipo cândida ou Leptotrix vaginalis foi confirmada em todos os casos pela citologia corada, embora os dois métodos citológicos revelem-se insuficientes na identificação do Leptotrix ${ }^{21}$. A observação de Candida sp em $22,6 \%$ dos exames a fresco confirma sua prevalência como causa de infecção vaginal durante a gravidez $z^{13,17,22,23}$. Em 33,7\% dos exames corados identificaram-se leveduras isoladas ou associadas a colpites bacterianas. A literatura $^{24}$ não considera a citologia corada pelo método de Papanicolaou método sensivel para o diagnóstico das infecções fúngicas sintomáticas. A citologia corada revelou sua capacidade em reconhecer a presença dos esporos e fungos como a Candida guillermondii, Torupsis glabrata e Geotrichum candidum, estruturas que não formam micélios e se apresentam como diminutos esporos com baixa refringência, soltos ou agrupados. Todavia, todas as estruturas fúngicas observadas na citologia corada foram designadas no laudo como candidíase. Em duas gestantes conseguiuse, no exame direto a fresco, identificar a Geotrichum candidum, representando $4,3 \%$ das micoses encontradas no grupo estudado. O uso do $\mathrm{KOH}$ a $10 \%$, provocando lise das estruturas que não sejam leveduras, permite fácil reconhecimento da Candida albicans com suas pseudo-hifas e esporos, mesmo que estas estruturas estejam pouco representadas. A citologia corada revelase, entretanto, melhor método na identificação das leveduras pelos motivos anteriormente enunciados. O cálculo de kappa demonstrou com o valor de 0,482 moderada concordância entre os dois métodos analisados.

Em 2,3\% dos casos encontraram-se no exame a fresco fusobacterium, bacilos anaeróbicos longos e finos, semelhante ao Leptotrix vaginalis, porém de menor tamanho. A citologia corada não os identificou nestes casos, diagnosticando-os como colpite do tipo inespecífica. Por ausência de diagnóstico pela técnica de Papanicolaou o índice kappa não pôde ser calculado.

Houve importante discordância quanto aos diagnósticos de processos inflamatórios designa- dos colpites inespecíficas entre o exame direto a fresco $(17,5 \%)$ e a citologia corada $(50,9 \%)$. O critério adotado na leitura direta baseou-se na presença de mais de 10 neutrófilos polimorfonucleares por célula vaginal epitelial ${ }^{25}$ esparsos no campo microscópico ou, mais raramente, agrupados como nas colpites purulentas por cocos e a ausência de agentes microbianos específicos. A flora vaginal aeróbia e anaeróbia observada na microscopia era representada por cocos, cocobacilos e bastonetes, não apresentando os critérios plenos de Amsel. A alta percentagem de laudos de processos inflamatórios na citologia corada deve-se ao não reconhecimento e diagnóstico da vaginose bacteriana, método já descrito como não eficaz no diagnóstico desta síndrome polimicrobiana. A avaliação do grau de concordância expressa $(k a p p a=0,2)$ revela a baixa correlação do diagnóstico de colpites inespecíficas entre os métodos citológicos avaliados.

O percentual $(36,5 \%)$ de esfregaços apresentando flora vaginal normal na citologia a fresco concordou com o observado na literatura $(35,9 \%)^{26}$. Todavia, os laudos de flora bacteriana sem sinais inflamatórios na citologia corada $(3,7 \%)$ demonstram resultados diversos do exame citológico direto. A explicação baseia-se provavelmente no encontro de numerosos lactobacilos fragmentados pelo processo de coloração, fato já observado nas citologias coradas pelo Gram ${ }^{25}$. A associação dos bacilos de Döderlein fragmentados e expressos como pequenos bastonetes ou microbacilos associados a presença de neutrófilos polimorfonucleares, normais em pequena quantidade na gravidez, pode induzir o laudo de processo inflamatório, sobretudo ao examinador quase sempre não afeito as queixas clínicas e ao aspecto do material colhido. O índice kappa de 0,2 demonstra nitidamente a baixa correlação entre os métodos empregados para identificar os esfregaços apresentando flora vaginal normal.

A gravidez, pela intensa ação estrogênica, induz a produção de importante flora de lactobacilos, representada por bastonetes de tamanho variáveis, não dotados de movimentos próprios, vistos sobrenadando nas correntes do soro fisiológico. A exacerbação desta flora lactobacilar determina a observação no exame a fresco de células epiteliais rotas, núcleos soltos e dispersos no campo microscópico, caracterizando o que chamamos de esfregaço citolítico, considerado normal quando discreto. $\mathrm{O}$ exagero deste fenômeno aumenta a descamação epitelial da vagina, propiciando surgimento de corrimento claro por vezes associado a ardência vaginal e/ou prurido. No exame a fresco caracterizamos os esfregaços citolíticos, 
quando a lise celular associa-se à flora vaginal normal, embora observem-se as queixas acima referidas. O exame a fresco neste estudo comparativo demonstrou de forma inequívoca ser melhor método propedêutico na avaliação dos elementos não epiteliais, diagnosticando, de maneira fácil e rápida, a higidez ou as alterações da flora vaginal, capazes em determinadas situações, como nas tricomoníases ou gardnereloses, de comprometer, se não tratadas, o bom resultado gestacional $^{4,27-29}$. Enfatizamos a importância do aprendizado e utilização, como rotina, do exame a fresco do conteúdo vaginal mesmo nas gestantes assintomáticas. No material estudado, em concordância com a literatura ${ }^{5}$, os critérios de Amsel foram observados em 53,2\% de gestantes assintomáticas. Somente quando indagadas, por vezes, referiam discreto corrimento claro sem outras características.

Conclui-se que a microscopia direta e a fresco combinada ao exame especular representa o melhor e mais rápido método propedêutico nas vaginites sintomáticas. Todavia, ressaltamos a utilização da colpocitologia corada na rotina prénatal como método propedêutico importante nas avaliações citoplasmáticas e nucleares das células cervicovaginais, permitindo pelas suas alterações sinalizar agressões viróticas, como as do papovavírus e do herpesvírus, as atipias indeterminadas e as alterações displásicas e neoplásicas.

\section{ABSTRACT}

Purpose: to analyze vaginal contents using the fresh wet mount of a cytological exam in the first prenatal visit of women with or without genital complaints and correlate the conclusion with the results from the Pap smears. Microscopy during pregnancy should be valued and recognized as a method capable of providing immediate diagnosis in $90 \%$ of bacterial vaginosis, candidiasis and trichomoniasis cases. Methods: a prospective study was performed in 216 pregnant women selected from the prenatal department of a public hospital, between October 30, 2001 and November 12, 2002. Two samples were collected from the posterior vaginal vault and deposited onto two separate microscope slides. To one slide, a droplet of $0.9 \% \mathrm{NaCl}$ was applied and to the other, a droplet of $10 \% \mathrm{KOH}$. Both slides were covered with a coverslip for immediate microscopic evaluation. Tests were perfomed in one drop of the material to examine $\mathrm{pH}$ and whiff. The microscopic examination of the material was carried out at a 100X, 400X and exceptionally 1000X magnification. Pap smears were performed in all pregnant patients. The correlation between the results of the utilized cytological methods was perfomed by the kappa coefficient, which evaluates the concordance for quality variables.

Results: the findings of the normal vaginal microflora in the fresh wet mount were $7.8 \%$, representing the most observed cytological aspect, and without correspondence with the $3.70 \%$ verified by the Pap smears. In the fresh wet mount, bacterial vaginosis was found in $30.9 \%$ and candidiasis in $7.9 \%$ of the cases. However, in the Pap smears no similar event occurred, the diagnosis being 0.7 and 24.3\%, respectively. The absence of a diagnosis correlation of nonspecific bacterial vaginitis by direct microscopy (17.5\%) and Pap smears (51.3\%) is probably due to the undervalued diagnosis of bacterial vaginosis by the latter method. The diagnosis of Trichomonas vaginalis observed in both cytological methods (3.70 and 2.78\%) represents a low prevalence of these parasites in the course of pregnancy. The kappa coefficient between the two cytological procedures in the several microbiological findings showed low correlation of the diagnosis of bacterial vaginosis with nonspecific vaginitis, as well as the normal vaginal flora.

Conclusions: although the Pap smear presents the best accuracy of the diagnosis of yeast without pseudomycelium, the fresh wet mount has shown to be a better appraiser of nonepithelial cells the vaginal smears. Because Pap smears allow a better evaluation of vaginal epithelial cells, they represent the most important tool to show the aggressions and reactions of the nucleus and cytoplasm.

KEYWORDS: Prenatal care. Vaginal cytology. Vaginitis in pregnancy.

\section{Agradecimentos}

Ao Professor-adjunto David Dorigo, bioestatístico da Disciplina de Informática Médica da Faculdade de Ciências Médicas da UERJ, pela valiosa colaboração na análise estatística.

\section{Referências}

1. Silva Filho AR, Burlá JM. Citologia vaginal a fresco: importância e limitações. Femina 2002; 30:377-80.

2. Goldenberg RL, Thompson CBS. As origens infecciosas responsáveis pela natimortalidade. Am J Obstet Gynecol (Ed. Bras) 2004; 5:49-62.

3. Goldenberg RL, Hauth JC, Andrews WW. Intrauterine infection and preterm delivery. N Engl $\mathrm{J}$ Med 2000; 342:1500-7.

4. Gjerdingen D, Fontaine P, Bixby M, Santilli J, Welsh $\mathrm{J}$. The impact of regular vaginal $\mathrm{pH}$ screening on the diagnosis of bacterial vaginosis in pregnancy. $\mathrm{J}$ Fam Pract 2000; 29:39-43. 
5. Priestley CJ, Kinghorn GR. Bacterial vaginosis. $\mathrm{Br}$ J Clin Pract 1996; 50:331-4.

6. Amsel R, Totten PA, Spiegel CA, Chen KC, Eschenbach D, Holmes KK. Nonspecific vaginitis: diagnostic criteria and microbial and epidemiologic associations. Am J Med 1983; 74:14-22.

7. James JA, Thomason JL, Gelbart SM, Osypowski P, Kaiser P, Hanson L. Is trichomoniasis often associated with bacterial vaginosis in pregnant adolescents ? Am J Obstet Gynecol 1992; 166:859-63.

8. Fleis JL. Measuring nominal scale agreement among many rates. Psychol Bull 1971; 76:378-82.

9. Molinero LM. Medidas de concordancia para variables cualitativas. 2001 Dic. [acesso em: dez. 2001]. Disponivel em: URL: http://www.seh-lelha.org/ concor2.htm.

10.Di Bartolomeo S, Rodriguez Fermepin M, Sauka DH, Torres RA. Prevalence of associated microorganisms in genital discharge, Argentina. Rev Saúde Pública 2002; 36:545-52.

11. Morris M, Nicoll A, Simms I, Wilson J, Catchpole M. Bacterial vaginosis: a public health review. BJOG 2001; 108:439-50.

12.McGregor JA, French JI. Bacterial vaginosis in pregnancy. Obstet Gynecol Surv 2000; 55 (Suppl 1):S119.

13.Simões JA, Giraldo PC, Faundes A. Prevalence of cervicovaginal infections during gestation and accuracy of clinical diagnosis. Infect Dis Obstet Gynecol 1998; 6:129-33.

14. Royce RA, Jackson TP, Thorp JM Jr, et al. Race/ ethnicity, vaginal flora patterns, and $\mathrm{pH}$ during pregnancy. Sex Transm Dis 1999; 26:96-102.

15.Wang J. Bacterial vaginosis. Prim Care Update Ob Gyns 2000; 7:181-5.

16. Hillier SL. Diagnostic microbiology of bacterial vaginosis. Am J Obstet Gynecol 1993; 169:455-9.

17.Greene JF $3^{\text {rd }}$, Kuehl TJ, Allen SR. The papanicolaou smear: inadequate screening test for bacterial vaginosis during pregnancy. Am J Obstet Gynecol 2000; 182:1048-9.

18. Hillier SL, Krohn MA, Rabe LK, Klebanoff SJ, Eschenbach DA. The normal vaginal flora, H2O2producing lactobacilli, and bacterial vaginosis in pregnant women. Clin Infect Dis 1993; 16 (Suppl 4):S273-81.
19.Krieger JN, Tam MR, Stevens CE, et al. Diagnosis of trichomoniasis: comparison of conventional wetmount examination with cytologic studies, cultures, and monoclonal antibody staining of direct specimens. JAMA 1988; 259:1223-7.

20.Franklin TL, Monif GR. Trichomonas vaginalis and bacterial vaginosis. Coexistence in vaginal wet mount preparations from pregnant women. J Reprod Med 2000; 45:131-4.

21.Loiudice L, De Vito D, Abbatecola T, Mastrorilli A . Detection of Leptotrix vaginalis in obstetric pathology. Clin Exp Obstet Gynecol 1982; 9:148-53.

22. Casanova Roman G, Narcio Reyes LE, Ortiz Ibarra FJ, Betran Zuniga M, Castelazo Morales E. Usefulness of fresh wet mount examination in the diagnosis of vaginal candidiasis. Ginecol Obstet Mex 1997; 65:87-91.

23. Benito Vilela FJ, Aguilera Zubizarreta E, Cuesta Perez-Camino A, et al. Prevalence of vaginal candidiasis in a low-risk obstetric population in Santander. Aten Primaria 2000; 25:103-6.

24.Donders GG, van Straeten D, Hooft P, De Wet GH. Detection of Candida cell forms in Pap smears during pregnancy. Eur J Obstet Gynecol Reprod Biol 1992; 43:13-8.

25.Donders GG, Vereecken A, Dekeersmaecker A, Van Bulck B, Spitz B. Wet mount microscopy reflects functional vaginal lactobacillary flora better than Gram stain. J Clin Pathol 2000; 53:308-13.

26. Bornstein J, Lakovsky Y, Lavi I, Bar-Am A, Abramovici $\mathrm{H}$. The classic approach to diagnosis of vulvovaginitis: a critical analysis. Infect Dis Obstet Gynecol 2001; 9:105-11.

27. Carey JC, Klebanoff MA. Bacterial vaginosis and other asymptomatic vaginal infections in pregnancy. Curr Womens Health Rep 2001; 1:14-9.

28.Kimberlin DF, Andrews WW. Bacterial vaginosis: association with adverse pregnancy outcome. Semin Perinatol 1998; 22:242-50.

29.Pastorek JG $2^{\text {nd }}$, Cotch MF, Martin DH, Eschenbach DA. Clinical and microbiological correlates of vaginal trichomoniasis during pregnancy. The Vaginal Infections and Prematurity Study Group. Clin Infect Dis 1996; 23:1075-80. 